\title{
Development and adaptation of patient- reported outcome measures for patients who experience itch associated with primary biliary cholangitis
}

\author{
Mona L. Martin ${ }^{1 *}$, Larissa Stassek', Steven I. Blum² ${ }^{2}$, Ashish V. Joshi ${ }^{2}$ and David Jones ${ }^{3}$
}

\begin{abstract}
Purpose: To conduct qualitative interviews to evaluate and refine the Itch Diary (ID) and weekly version of the PBC-40 in patients with itching associated with primary biliary cholangitis (PBC).

Methods: Twenty adults with self-reported PBC diagnoses and recent/ongoing itching of at least moderate intensity participated in face-to-face qualitative combined concept elicitation (CE) interviews and cognitive interviews after completing the morning and evening versions of the ID and weekly version of the PBC-40. These questionnaires were evaluated to confirm saturation of concepts of interest and cognitively test the English language versions of the measures in patients with PBC in the US and Canada. Transcripts were organized into descriptions of PBC-related symptoms and symptom-related impacts using a structured coding framework. Two waves of interviews were conducted; revisions made after wave 1 were further tested in wave 2.

Results: Interview results confirmed the relevance of concepts presented in the PBC-40 and ID to patients' experiences. Saturation of concept was achieved. Itching-related signs and symptoms (46\%) were the most commonly expressed symptom concept in the CE interviews followed by energy-related (14\%) and additional signs/symptoms (13\%). Several changes to the ID were made in response to cognitive interview results. Changes to the PBC-40 included adaptations from British to North American English, and the appropriateness of a 7-day recall period was confirmed.

Conclusions: Relevance of the symptom and impact concepts in the ID to measure PBC-related itch were confirmed. Adaptation of the PBC-40 to a weekly recall period and for North American English was successful.
\end{abstract}

Keywords: Itch, Patient-reported outcomes, Primary biliary cholangitis, PBC, Pruritus, Qualitative

\section{Introduction}

Primary biliary cholangitis (PBC), previously known as primary biliary cirrhosis, is a chronic autoimmune disease of the liver in which intrahepatic small bile ducts are selectively destroyed by inflammatory cells $[1,2]$. The disease is progressive and eventually results in liver fibrosis [2]. PBC is relatively uncommon, with a prevalence of up to 39.2 per 100,000 in the United States [3], and has a strong predominance in women $[3,4]$.

\footnotetext{
* Correspondence: martin@hrainc.net

${ }^{1}$ Health Research Associates, Inc., 6505 216th St. SW, Suite 105, Mountlake

Terrace, WA 98043, USA

Full list of author information is available at the end of the article
}

Itching (pruritus) is an extrahepatic symptom of $\mathrm{PBC}$ that occurs in an estimated $55 \%$ of patients [5]. The itch may be severe and can have a significant impact on patients' health-related quality of life [6]. In a survey of 238 patients with $\mathrm{PBC}$, the itching sensation was described as "bugs crawling" or "relentless" and 3.6\% reported they scratched until they bled [7]. Nearly three-quarters of patients reported that the itch interfered with sleep [7]. Scratching brings little to no relief and intense scratching may cause serious damage to the skin [8]. The bile acid sequestrant, cholestyramine is the only US Food and Drug Administration (FDA)-approved treatment for PBCrelated itch, but it has an unpleasant taste and can cause gastrointestinal side effects, limiting its clinical uptake. 
Additionally, it should not be taken within 4 to $6 \mathrm{~h}$ of many other common medications (e.g., warfarin, digoxin, seizure medications, levothyroxine, antibiotics, etc) $[1,8]$.

Itch is a sensation that cannot be directly observed, and is only known to the individual, making its assessment subjective and difficult to quantify [8]. Patient-reported outcome (PRO) measures for PBC-related itch are limited. Tools used to date include a simple grading of worst itch over a certain period (e.g., the past 7 days) on a numeric rating scale (e.g., 0 to 10) or on a Visual Analogue Scale (VAS) and the 5-D itch scale [8]. The 5-D itch scale is a brief and easy-to-complete measure designed to specifically evaluate the extent and impact of itch across a range of conditions, but it was not developed using qualitative interviews with $\mathrm{PBC}$ patients [9]. On the other hand, the PBC-40 is a PBC-specific, health-related quality-of-life questionnaire, but it only has 3 questions to assess itch and these questions may not be sufficient to cover the spectrum of itching, which is a key symptom in this target population [10]. Additionally, the original version of the PBC-40 has a 4-week recall period, which may not be ideal for measuring daily variability in patient's itch experience.

The Patient Reported Symptoms Questionnaire ("Itch Diary") was developed to meet the need for a PBCspecific itch PRO measure and was based on key concepts in the PBC-40 [11, 12]. The questionnaire focuses on itch, but also contains items for a few other PBC symptoms such as fatigue and diarrhea. Initial cognitive testing was conducted through interviews with 10 participants with $\mathrm{PBC}$, and the Itch Diary was preliminarily used in a phase 2a safety and tolerability study of GSK2330672, an ileal bile acid transporter inhibitor under development for PBC-related itch [13]. In order to ensure greater accuracy in the recall of symptoms, the phase 2a study also preliminarily evaluated the PBC-40 during a 2-week placebo run-in period using a "past 2 weeks" recall period, in contrast to the original recall period of "last 4 weeks" $[10,14]$. However, it was still unclear as to whether the list of symptoms was complete in terms of key concepts relevant to those with PBC.

An integral part of developing quality-of-life measures is to conduct qualitative patient interviews and such interviews are recommended by the FDA for the development of PRO measures $[15,16]$. The objective of the current study was to further develop and cognitively test English versions of the Itch Diary and the weekly version of the PBC-40 in North American individuals with PBC and related itching, and to identify any other potential concepts that might be relevant to patients' experiences.

\section{Methods}

\section{Study design and participants}

While the qualitative sample of ten patients in the previous study at times may be acceptable for rare conditions, it was still unclear whether the list of symptoms identified in the earlier study was complete in terms of the key concepts relevant to people with $\mathrm{PBC}$, and whether the content was transferrable to other countries and cultures. Therefore, we conducted additional qualitative interviews in patients with PBC to confirm saturation of the concepts of interest and the applicability of these concepts within the US and Canada. In-person qualitative interviews consisting of concept elicitation (CE) and cognitive portions were conducted in the US and Canada to collect data for confirming content relevance, instrument feasibility, and saturation of concept for the Itch Diary and the weekly version of the $\mathrm{PBC}-40$. Interviews lasted for about $90 \mathrm{~min}$, beginning with the $\mathrm{CE}$ portion of the interview, then completion of questionnaires of interest (PBC-40, Itch Diary) as well as some additional secondary questionnaires (Weekly Gastrointestinal Diary; Patient Global Impression of Severity for Itch [PGIS-Itch] and Patient Global Impression of Change for Itch [PGIC-Itch]; and 5-D itch scale), followed by the cognitive portion of the interview.

Men and women aged 18 to 80 years who self-reported a diagnosis of $\mathrm{PBC}$ were recruited via local and national patient groups. Participants were required to have ongoing itching of at least moderate intensity (equivalent to a score of $\geq 4$ on the numerical response scale [NRS; range $0-10$ ]) during the previous 8 weeks. Individuals with a selfreported history of liver disease of other etiology or reporting other highly symptomatic medical conditions (i.e., inflammatory bowel disease, chronic plaque psoriasis, eczema, etc) were excluded. As PBC predominantly affects women $[3,4]$, a majority of the sample was expected to be female.

Study recruitment was conducted via advertisements to members of patient groups in the US and Canada: PBCers and the Canadian PBC Society. The study was conducted in compliance with Health Insurance Portability and Accountability Act regulations, and all participants provided written informed consent. The study was approved by an Institutional Review Board (Quorum Review IRB, Seattle, WA, USA).

\section{Data collection}

Demographic and basic comorbidity data were collected from each participant. Those who were willing, signed a Medical Information Release Waiver giving their consent for additional limited medical information to be obtained from their medical provider. Information collected from the medical provider, when authorized, included date of $\mathrm{PBC}$ diagnosis, current and past medications for itching/ pruritus, previous history of liver transplant (yes/no), and, when possible, the most recent bilirubin and alkaline phosphatase lab results. 


\section{Interview process}

Interviewers were experienced in interviewing techniques for PRO measurement development and in conducting one-on-one interviews across a wide range of therapeutic areas. Training for the interviewers included an instruction session specific to the study, review of the interview guide, and observed practice interviews.

Interviews were conducted in 2 waves of 10 participants each. Revisions to the PRO measures were made in response to participant input from the first wave, and then tested in the second wave. During the CE portion of the interviews, participants were asked open-ended questions in order to elicit spontaneous reports of the patient's experience, followed by probing questions designed to more fully explore participant experiences with $\mathrm{PBC}$ symptoms (including frequency, severity, and variation of symptoms) and the impact of $\mathrm{PBC}$ on emotions, daily activities, social functioning, sleep, etc. During the cognitive portion of the interviews, participants were asked a series of structured and semi-structured questions designed to obtain feedback on the PRO measures. Topics covered were the participants' interpretation of the individual items, how they regarded the fit and adequacy of the response scales and recall periods, and how comfortable they were with the terminology used. Participants were also asked to discuss the relevance of PRO items and whether any other important concepts were missing and should be considered for addition.

PRO measures of interest were administered to each participant on paper between the $\mathrm{CE}$ and cognitive portions of the interview. The PROs of main interest were the Itch Diary (AM and PM versions) and a weekly version of the PBC-40 that used a 7-day recall period as opposed to the original 4-week recall period [10]. The PBC-40 contains 40 questions covering 6 domains (symptoms, itch, fatigue, cognition, social, and emotional), and 3 additional questions measuring general health status [10]. The PGIS-Itch and PGIC-Itch were also evaluated to confirm their relevance as suitable anchor measures for use in future studies to assess the psychometric properties of the Itch Diary and the weekly version of the PBC-40.

\section{Data analysis}

Transcripts from the CE portion of the interview were organized into descriptions of PBC-related symptoms and symptom impacts by developing a coding framework and coding dictionary. Two coders were used during the study. Inter-rater agreement was evaluated by independent dual coding of 2 of the 20 transcripts and comparing the coding differences and expressing coding consistency by percentage of agreement in the codes assigned.

A saturation table was used to track symptoms and impacts from the concept elicitation portion of the interviews. The transcripts were ordered chronologically, based on interview completion date, and then grouped into four groups of five transcripts each. Concept saturation was then evaluated by comparing the codes in each new transcript group with the codes in the previous group to identify newly appearing information. When new codes no longer appeared, no new information was being obtained; this is called "saturation of concept" meaning no further information is likely to be gained by continuing interviews in the same population.

Descriptive statistics were generated for demographic and concept rating data. Information for the cognitive portion of the interviews was collected into a summary grid that organized and related the response from each participant to the item that was queried. Difficulties in understanding the item content were also noted in the cognitive summary grid.

\section{Results}

\section{Population characteristics}

Of the 20 participants interviewed in the study, the mean age was 57.4 years and $90 \%$ were women (Table 1 ). Most (90\%) participants were white and 10\% were Hispanic. Fourteen were in the US (Seattle, WA; Austin, TX; El Paso, TX; Lansing, MI; Grand Rapids, MI; New York City, NY; and San Francisco, CA) and 6 were in Canada (Toronto, ON; Victoria, BC; and Vancouver, BC). The majority (55\%) were employed full-time, whereas $30 \%$ were retired. The most common comorbidities were allergies (50\%) and arthritis (50\%), and the mean severity of worst itch based on a 101-point NRS was 89.3 (a score of 100 represents the "Worst Itching You Can Imagine" and 0 represents "NO Itching at All").

Sixteen patients signed the optional Medical Information Release Form authorizing the study team to request limited medical information from their medical provider. Of the 16 forms sent to providers, 10 were returned. Four additional patients brought their own medical records to the interviews. Therefore, additional limited medical information from medical providers was available for 14 participants. PBC diagnosis was confirmed in all 14 patients, with a mean (standard deviation) duration of disease of 9.6 (6.0) years. Twelve of these 14 participants $(86 \%)$ had received ursodeoxycholic acid (past or present) to treat their PBC. Only 4 reported they were currently using medication to relieve their itching.

Patients who were screened but did not fully meet the eligibility criteria were considered on an individual basis to determine whether the particular criteria deviation might lead to confounding or conflict with the study design or objectives. Four of these subjects were authorized to participate despite not meeting one or more eligibility criteria, one subject cancelled the interview and the three remaining subjects were interviewed and included in the analysis. Of those included, 1 patient reported 
Table 1 Participant demographic and disease characteristics

\begin{tabular}{|c|c|}
\hline Characteristic & $N=20$ \\
\hline \multicolumn{2}{|l|}{ Age, y } \\
\hline Mean (SD) & $57.4(11.2)$ \\
\hline Range & $32-74$ \\
\hline Female, $n(\%)$ & $18(90)$ \\
\hline \multicolumn{2}{|l|}{ Race, $n(\%)$} \\
\hline White & $18(90)$ \\
\hline Hispanic & $2(10)$ \\
\hline \multicolumn{2}{|l|}{ Highest level of education completed, $n(\%)$} \\
\hline High school & $1(5)$ \\
\hline Some college & $7(35)$ \\
\hline Bachelor's degree & $6(30)$ \\
\hline Graduate or professional school & $6(30)$ \\
\hline \multicolumn{2}{|l|}{ Current employment status, $n(\%)$} \\
\hline Full time & $11(55)$ \\
\hline Part time & $1(5)$ \\
\hline Unemployed for > 1 year & $1(5)$ \\
\hline Retired & $6(30)$ \\
\hline Unable to work because of PBC, CPS/fibromyalgia & $1(5)$ \\
\hline \multicolumn{2}{|l|}{ Household income, US $\$, n(\%)$} \\
\hline$\$ 15,000-\$ 24,999$ & $2(10)$ \\
\hline$\$ 25,000-\$ 34,999$ & $1(5)$ \\
\hline$\$ 35,000-\$ 49,999$ & $2(10)$ \\
\hline$\$ 50,000-\$ 74,999$ & $6(30)$ \\
\hline$\$ 75,000-\$ 99,999$ & $2(10)$ \\
\hline$\$ 100,000-\$ 124,999$ & $1(5)$ \\
\hline$\geq \$ 125,000$ & $5(25)$ \\
\hline Declined to answer & $1(5)$ \\
\hline \multicolumn{2}{|l|}{ Comorbidities, $n(\%)^{\mathrm{a}}$} \\
\hline Allergies (hay fever, chronic sinus trouble, other) & $10(50)$ \\
\hline Arthritis or rheumatism & $10(50)$ \\
\hline Asthma or other severe lung problems ${ }^{b}$ & $4(20)$ \\
\hline Back problems (including disc or spine) & $7(35)$ \\
\hline Depression & $2(10)$ \\
\hline Diabetes or high blood sugar & $3(15)$ \\
\hline Headache or migraine & $3(15)$ \\
\hline Heart trouble $^{c}$ & $1(5)$ \\
\hline High blood pressure or hypertension & $7(35)$ \\
\hline Nervousness or anxiety disorder & $2(10)$ \\
\hline Thyroid problems & $1(5)$ \\
\hline Trouble seeing (even with glasses or contact lenses) & $4(20)$ \\
\hline \multicolumn{2}{|l|}{ Itch NRS (scale 0-100) } \\
\hline Severity of worst itch, mean (SD) & $89.3(14.1)$ \\
\hline Severity of usual amount of itch, mean (SD) & $50.5(24.5)$ \\
\hline
\end{tabular}

CPS, chronic pain syndromes; NRS numerical response scale; $P B C$ primary biliary cholangitis; $S D$, standard deviation; US, United States

${ }^{a}$ One participant each (5\%) reported celiac disease, chronic reflux, fibromyalgia, hepatitis C, mixed nonspecific autoimmune disease, osteoarthritis, osteoporosis, polyps, Raynaud's disease, Sjogren's syndrome, or sphincter of Oddi dysfunction ${ }^{b}$ Chronic bronchitis, chronic obstructive pulmonary disorder, or emphysema 'Angina, congestive heart failure, coronary artery disease, use of cardiac pacemaker dDuring the concept elicitation portion of the interview, participants were asked to complete a series of rating exercises using a NRS, with the 0 end of the scale representing "NO Itching at All," and 100 representing "Worst Itching You Can Imagine" average itching of level 3 (just below the threshold of 4), although this patient reported having itching above a 4 at times during the recall period; 1 patient had been diagnosed with hepatitis $\mathrm{C}$, but had been declared cured after treatment for the infection; and 1 patient reported infrequent minor flare-ups of eczema but was not experiencing eczema during screening or the interview for the current study.

\section{Concept elicitation (CE) interviews}

Saturation of concept (the point where no new concepts emerged) for the Itch Diary was reached by the end of the third transcript group (i.e., 4 groups with 5 transcripts each). Inter-rater agreement in assignment of codes between the 2 raters was high at $94 \%$ and $95 \%$ for the 2 dual-coded transcripts.

The CE portion of the interviews confirmed relevance of the concepts presented in the items of the PBC-40 and Itch Diary (both AM and PM versions). Itchingrelated signs and symptoms were reported by all patients, and was the most commonly expressed symptom subdomain when assessed by symptom concept code frequency (46\% of all symptom expressions) followed by energy-related concepts (14\% of total symptoms expressed) and additional signs and symptoms (13\% of total symptoms expressed) (Table 2). Specific codes in terms of how patients described the term and additional descriptors are reported in Table 2.

During the CE portion of the interview, participants were given the opportunity to spontaneously report symptoms related to their $\mathrm{PBC}$ before follow-up probing questions were asked. The symptom concepts most often mentioned spontaneously were "fatigue" (75\%; 15/ 20 participants) and "itching on the legs" (75\%; 15/20 participants). Other common spontaneously reported symptom concepts were "itching on the arms" (55\%; 11/20 participants), "itching on the side" (45\%; 9/20 participants), and "itching on the back" (45\%; 9/20 participants). Followup probing questions did not notably increase the reports related to itching, although the number of participants reporting weakness, gastrointestinal signs and symptoms, cognitive signs and symptoms, and pain and discomfort were markedly increased (Table 3).

During the interview, participants were asked to refer to the symptoms they had described and identify the top 1 or 2 symptoms that were the worst for them. The symptoms most commonly chosen were itching (worst in $40 \%$ of participants, second worst in $25 \%$ of participants) and fatigue (worst in 35\% of participants, second worst in $35 \%$ of participants). Participants identified the most common location for itching as legs (75\%), followed by arms (65\%), torso (60\%), and feet (50\%).

A series of questions was asked during the $\mathrm{CE}$ portion of the interviews to explore the impact of $\mathrm{PBC}$ on patients' lives and the language used by participants to describe these 
Table 2 Summary of symptom concept code frequency totals by subdomain

\begin{tabular}{|c|c|c|}
\hline $\begin{array}{l}\text { PBC Symptom } \\
\text { Subdomains and } \\
\text { Concepts }\end{array}$ & $\begin{array}{l}\text { Total Language } \\
\text { Expressions Within } \\
\text { Concept, } n(\%) \\
N=642\end{array}$ & $\begin{array}{l}\text { Transcripts Contributing } \\
\text { to Concept Expressions, } \\
n(\%) \\
N=20\end{array}$ \\
\hline $\begin{array}{l}\text { Itching-related signs and } \\
\text { symptoms }\end{array}$ & $293(46)$ & $20(100)$ \\
\hline Itching & $254(39.6)$ & $20(100)$ \\
\hline Hives & $12(1.9)$ & $3(15)$ \\
\hline Burning & $9(1.4)$ & $3(15)$ \\
\hline Rash & $9(1.4)$ & $3(15)$ \\
\hline Tingling & $8(1.2)$ & $4(20)$ \\
\hline Dry patches & $1(0.2)$ & $1(5)$ \\
\hline $\begin{array}{l}\text { Energy-related signs and } \\
\text { symptoms }\end{array}$ & $87(14)$ & $18(90)$ \\
\hline Fatigue & $44(6.9)$ & $17(85)$ \\
\hline Tiredness & $16(2.5)$ & $9(45)$ \\
\hline Low energy & $14(2.2)$ & $6(30)$ \\
\hline Exhaustion & $8(1.2)$ & $7(35)$ \\
\hline Weakness & $5(0.8)$ & $4(20)$ \\
\hline $\begin{array}{l}\text { Additional signs and } \\
\text { symptoms }\end{array}$ & $86(13)$ & $19(95)$ \\
\hline Other symptoms ${ }^{a}$ & $20(3.1)$ & $11(55)$ \\
\hline Dry eyes & $13(2.0)$ & $10(50)$ \\
\hline Gallstones & $9(1.4)$ & $8(40)$ \\
\hline Dry mouth & $8(1.2)$ & $8(40)$ \\
\hline Weak/brittle bones & $8(1.2)$ & $5(25)$ \\
\hline Fat deposits on skin & $8(1.2)$ & $6(30)$ \\
\hline Darkening of skin & $8(1.2)$ & $6(30)$ \\
\hline Hair loss & $3(0.5)$ & $2(10)$ \\
\hline Jaundice & $3(0.5)$ & $2(10)$ \\
\hline Sleep disturbance & $3(0.5)$ & $3(15)$ \\
\hline Swelling & $3(0.5)$ & $3(15)$ \\
\hline Pain and discomfort & $77(12)$ & $19(95)$ \\
\hline Joint pain/aches & $23(3.6)$ & $10(50)$ \\
\hline Discomfort in right side & $21(3.3)$ & $11(55)$ \\
\hline Muscle pain/aches & $9(1.4)$ & $5(25)$ \\
\hline General pain & $8(1.2)$ & $6(30)$ \\
\hline $\begin{array}{l}\text { Other pain and } \\
\text { discomfort }\end{array}$ & $8(1.2)$ & $8(40)$ \\
\hline Abdominal pain & $4(0.6)$ & $4(20)$ \\
\hline Bone pain/aches & $4(0.6)$ & $3(15)$ \\
\hline Gl signs and symptoms & $69(11)$ & $16(80)$ \\
\hline Diarrhea & $17(2.6)$ & $10(50)$ \\
\hline Nausea & $12(1.9)$ & $7(35)$ \\
\hline Abdominal bloating & $11(1.7)$ & $10(50)$ \\
\hline Other Gl symptoms & $10(1.6)$ & $7(35)$ \\
\hline
\end{tabular}

Table 2 Summary of symptom concept code frequency totals by subdomain (Continued)

\begin{tabular}{|c|c|c|}
\hline $\begin{array}{l}\text { PBC Symptom } \\
\text { Subdomains and } \\
\text { Concepts }\end{array}$ & $\begin{array}{l}\text { Total Language } \\
\text { Expressions Within } \\
\text { Concept, } n(\%) \\
N=642\end{array}$ & $\begin{array}{l}\text { Transcripts Contributing } \\
\text { to Concept Expressions, } \\
n(\%) \\
N=20\end{array}$ \\
\hline $\begin{array}{l}\text { Urgency with bowel } \\
\text { movements }\end{array}$ & $7(1.1)$ & $7(35)$ \\
\hline Greasy diarrhea & $6(0.9)$ & $5(25)$ \\
\hline Indigestion/heartburn & $3(0.5)$ & $3(15)$ \\
\hline Changes in appetite & $3(0.5)$ & $3(15)$ \\
\hline $\begin{array}{l}\text { Cognitive signs and } \\
\text { symptoms }\end{array}$ & $30(5)$ & $10(50)$ \\
\hline Difficulty concentrating & $11(1.7)$ & $7(35)$ \\
\hline $\begin{array}{l}\text { Difficulty remembering } \\
\text { things }\end{array}$ & $9(1.4)$ & $7(35)$ \\
\hline $\begin{array}{l}\text { Other cognitive } \\
\text { symptoms }\end{array}$ & $4(0.6)$ & $2(10)$ \\
\hline Brain fog & $3(0.5)$ & $2(10)$ \\
\hline Confusion & $3(0.5)$ & $2(10)$ \\
\hline
\end{tabular}

$G l$, gastrointestinal; $P B C$, primary biliary cholangitis

${ }^{a}$ Other symptoms include: bruises easily, cellulitis, changes in taste, chest infections, eye problems, fibromatosis, flushed, fluid in abdomen, heat intolerance, kidney stones, no hair growth, redness, restless legs, shingles, shortness of breath, and sweating

impacts. Changes in daily performance was the most commonly expressed impact subdomain when assessed by impact concept code frequency $(21 \%$ of total impact expressions) followed by emotional functioning ( $18 \%$ of total impact expressions) and sleep difficulties (17\% of total impact expressions) (Table 4).

Within these subdomains, the most frequently cited concepts overall were "scratching until skin is raw/infected" (38 expressions by 16 participants [80\%]) in the additional impacts subdomain, "difficulty staying asleep" (38 expressions by 16 participants [60\%]) in the sleep difficulties subdomain, "social activities limited" (37 expressions by 14 participants [70\%]) in the limitations to relationships and social functioning subdomain, "limitations at work" (34 expressions by 15 participants [75\%]) in the changes to daily performance subdomain, and "needing to change their diet" (32 expressions by 15 participants [75\%]) in the limitations to lifestyle and activities subdomain.

Similar to the symptom concepts, participants were allowed to spontaneously report impact concepts related to their $\mathrm{PBC}$ before follow-up probing questions were asked. The impact concepts most often mentioned spontaneously were "limitations at work" (65\%; 13/20 participants) and "difficulty staying asleep" (65\%; 13/20 participants). Other common spontaneously reported impact concepts were "needing to change their diet" (60\%; $12 / 20$ participants) and "scratching until skin is raw/infected" (55\%; 11/20 participants). Follow-up probing questions increased the 
Table 3 Spontaneous vs probed symptom expressions during the CE portion of the interviews

\begin{tabular}{|c|c|c|c|c|}
\hline \multirow[t]{2}{*}{ Symptom Reported, $n$ (\%) } & \multicolumn{4}{|c|}{ Participants, $N=20$} \\
\hline & Spontaneous & Probed & Not Affected & Not Reported \\
\hline \multicolumn{5}{|l|}{ Itching-related signs and symptoms } \\
\hline Itching on the legs & $15(75)$ & - & - & $5(25)$ \\
\hline Itching on the arms & $11(55)$ & $2(10)$ & - & $7(35)$ \\
\hline Itching on the back & $9(45)$ & $1(5)$ & - & $10(50)$ \\
\hline Itching on the sides & $9(45)$ & $1(5)$ & - & $10(50)$ \\
\hline Itching on the abdomen & $7(35)$ & $2(10)$ & - & $11(55)$ \\
\hline Itching on the head & $6(30)$ & - & - & $14(70)$ \\
\hline Itching on the feet & $3(15)$ & - & - & $17(85)$ \\
\hline Itching on the hands & $3(15)$ & - & - & $17(85)$ \\
\hline Itching on the face & $2(10)$ & $1(5)$ & - & $17(85)$ \\
\hline Itching on the chest & $1(5)$ & - & - & $19(95)$ \\
\hline Itching on the groin & $1(5)$ & - & - & $19(95)$ \\
\hline Hives & $1(5)$ & - & - & $19(95)$ \\
\hline Rash & $1(5)$ & - & - & $19(95)$ \\
\hline \multicolumn{5}{|l|}{ Energy-related signs and symptoms } \\
\hline Fatigue & $15(75)$ & $1(5)$ & $2(10)$ & $2(10)$ \\
\hline Tiredness & $6(30)$ & - & - & $14(70)$ \\
\hline Lack of energy & $3(15)$ & - & - & $17(85)$ \\
\hline Exhausted & $2(10)$ & - & - & $18(90)$ \\
\hline Weakness & $2(10)$ & $10(50)$ & $8(40)$ & - \\
\hline \multicolumn{5}{|l|}{ Gastrointestinal signs and symptoms } \\
\hline Nausea & $6(30)$ & - & - & $14(70)$ \\
\hline Diarrhea & $4(20)$ & $8(40)$ & $8(40)$ & - \\
\hline Other $^{\mathrm{a}}$ & $3(15)$ & $1(5)$ & - & $16(80)$ \\
\hline Abdominal bloating & $2(10)$ & $10(50)$ & $6(30)$ & $2(10)$ \\
\hline Changes in appetite & - & $5(25)$ & $14(70)$ & $1(5)$ \\
\hline Greasy diarrhea & $1(5)$ & $7(35)$ & $11(55)$ & $1(5)$ \\
\hline Urgency with bowel movements & - & $12(60)$ & $7(35)$ & $1(5)$ \\
\hline \multicolumn{5}{|l|}{ Cognitive signs and symptoms } \\
\hline Difficulty concentrating & $3(15)$ & $11(55)$ & $6(30)$ & - \\
\hline Difficulty remembering things & $2(10)$ & $12(60)$ & $6(30)$ & - \\
\hline \multicolumn{5}{|l|}{ Pain and discomfort } \\
\hline Bone pain/aches & $5(25)$ & $2(10)$ & - & $13(65)$ \\
\hline Muscle pain/aches & $4(20)$ & - & - & $16(80)$ \\
\hline Abdominal pain & $3(15)$ & $9(45)$ & $7(35)$ & $1(5)$ \\
\hline Discomfort in right side & $3(15)$ & $11(55)$ & $5(25)$ & $1(5)$ \\
\hline General pain & - & $4(20)$ & $4(20)$ & $12(60)$ \\
\hline Joint pain/aches & $3(15)$ & $2(10)$ & - & $15(75)$ \\
\hline Other ${ }^{b}$ & $1(5)$ & $1(5)$ & - & $18(90)$ \\
\hline \multicolumn{5}{|l|}{ Additional signs and symptoms } \\
\hline Dry eyes & $6(30)$ & $8(40)$ & $6(30)$ & - \\
\hline Difficulty staying asleep & $5(25)$ & $11(55)$ & $4(20)$ & - \\
\hline Dry mouth & $4(20)$ & $9(45)$ & $7(35)$ & - \\
\hline
\end{tabular}


Table 3 Spontaneous vs probed symptom expressions during the CE portion of the interviews (Continued)

\begin{tabular}{|c|c|c|c|c|}
\hline \multirow[t]{2}{*}{ Symptom Reported, $n$ (\%) } & \multicolumn{4}{|c|}{ Participants, $N=20$} \\
\hline & Spontaneous & Probed & Not Affected & Not Reported \\
\hline Hair loss & $4(20)$ & - & - & $16(80)$ \\
\hline Other $^{c}$ & $4(20)$ & - & - & $16(80)$ \\
\hline Difficulty falling asleep & $2(10)$ & $8(40)$ & $9(45)$ & $1(5)$ \\
\hline Weak/brittle bones & $2(10)$ & $1(5)$ & $17(85)$ & - \\
\hline Darkening of the skin & $1(5)$ & $7(35)$ & $12(60)$ & - \\
\hline Fatty deposits on skin & $1(5)$ & $5(25)$ & $14(70)$ & - \\
\hline Gall stones & - & $3(15)$ & $3(15)$ & $14(70)$ \\
\hline Jaundice & $1(5)$ & $1(5)$ & $18(90)$ & - \\
\hline Kidney stones & - & $5(25)$ & $9(45)$ & $6(30)$ \\
\hline Swelling & - & $10(50)$ & $10(50)$ & - \\
\hline
\end{tabular}

CE, concept elicitation

acid reflux, constipation, fewer stools, don't process vitamins/minerals properly

beadache, migraine

'Weight gain, weight loss, restless legs, sweating, skin flushed, heavy menstruation

number of participants reporting most of the impact concepts (Table 5).

Participants were also asked to choose 1 to 2 impacts that were the worst for them. Responses varied widely, but 3 participants (15\%) selected "general function/daily routine" and 2 participants (10\%) selected "reduced sleep quality."

\section{Cognitive interviews and PRO revisions}

The cognitive portion of the interviews resulted in several changes to the Itch Diary and PBC-40 (Table 6). During wave 1, 2 items were dropped from the Itch Diary (1 from the AM and 1 from the PM diary) because participants felt that these were very similar to other items. The question stems were changed in 6 items ( 1 in the AM and 5 in the PM diary) to make the items clearer and easier to answer. The response scale was changed from an NRS version to a verbal response scale (VRS) version in 1 item in the AM Itch Diary and 7 items in the PM Itch Diary to reduce confusion in interpretation of answers. For example, many of the questions asked "how much time..." and some participants interpreted the number options as percentages, whereas others interpreted the options as number of hours. Changing the response to a VRS helped to more clearly and consistently define each of the response options (i.e., "none of the time," "a little of the time," etc).

Further revisions were made to question stems and the response scale after wave 2 . These changes included additional wording changes to 1 of the items in the AM and PM diaries, as well as changes to the response options of these diaries; additionally, the NRS versions of select items were added back into the measure for use in an upcoming clinical trial for testing against the VRS versions.

Three of the item revisions in the PBC-40 during wave 1 were to adapt from British English in the original version to terms more common in North America (i.e., "holiday" vs "vacation"). During wave 2, additional revisions were made to 3 items to further clarify their meaning. For example, 1 item asked about aching in the long bones of the patient's arms and legs. Some participants had trouble responding because they experienced aching in the arms, but not in the legs or vice versa. Therefore, the

Table 4 Summary of impact concept code frequency totals by subdomain

\begin{tabular}{|c|c|c|}
\hline PBC Impact Subdomains and Concepts & $\begin{array}{l}\text { Total Participant Symptom } \\
\text { Expressions Within Concept, } n(\%) \\
N=571\end{array}$ & $\begin{array}{l}\text { Transcripts Contributing to } \\
\text { Concept Expressions, } n(\%) \\
N=20\end{array}$ \\
\hline Changes in daily performance & $119(21)$ & $18(90)$ \\
\hline Emotional functioning & $103(18)$ & $19(95)$ \\
\hline Sleep difficulties caused by itching or other symptoms & $98(17)$ & $18(90)$ \\
\hline Limitations to relationships and social functioning & $87(15)$ & $16(80)$ \\
\hline Limitations to lifestyle and activities & $84(15)$ & $20(100)$ \\
\hline Additional impacts ${ }^{a}$ & $80(14)$ & $19(95)$ \\
\hline
\end{tabular}

$P B C$, primary biliary cholangitis

${ }^{a}$ Decreased quality of life, economic burden, scratching until skin is raw or infected, treatment burden, physical discomfort, and weight gain 
Table 5 Spontaneous vs probed impact expressions during the CE portion of the interviews

\begin{tabular}{|c|c|c|c|c|}
\hline \multirow[t]{2}{*}{ Symptom Reported, $n$ (\%) } & \multicolumn{4}{|c|}{ Participants, $N=20$} \\
\hline & Spontaneous & Probed & Not Affected & Not Reported \\
\hline \multicolumn{5}{|l|}{ Emotional functioning } \\
\hline Anxiety & $7(35)$ & $2(10)$ & $3(15)$ & $8(40)$ \\
\hline Embarrassment & $5(25)$ & $1(5)$ & $3(15)$ & $11(55)$ \\
\hline Depression & $4(20)$ & $1(5)$ & $3(15)$ & $12(60)$ \\
\hline Worry & $3(15)$ & $5(25)$ & $3(15)$ & $9(45)$ \\
\hline Anger & $2(10)$ & $2(10)$ & $3(15)$ & $13(65)$ \\
\hline Frustration & $2(10)$ & $5(25)$ & $3(15)$ & $10(50)$ \\
\hline Stress & $2(10)$ & $4(20)$ & $3(15)$ & $11(55)$ \\
\hline Guilt & $1(5)$ & $3(15)$ & $3(15)$ & $13(65)$ \\
\hline Other $^{a}$ & $1(5)$ & - & - & $19(95)$ \\
\hline \multicolumn{5}{|l|}{ Changes in daily performance } \\
\hline Work & $13(65)$ & $2(10)$ & $3(15)$ & $2(10)$ \\
\hline General functioning/daily routine & $4(20)$ & $5(25)$ & $3(15)$ & $8(40)$ \\
\hline Housework/chores & $4(20)$ & $5(25)$ & $3(15)$ & $8(40)$ \\
\hline Needs to pace self & $3(15)$ & $11(55)$ & $6(30)$ & - \\
\hline Takes longer than usual to recover & $3(15)$ & $14(70)$ & $2(10)$ & $1(5)$ \\
\hline Takes longer than usual to complete tasks & $2(10)$ & $13(65)$ & $5(25)$ & - \\
\hline Need to force self & $1(5)$ & $12(60)$ & $7(35)$ & - \\
\hline Other $^{b}$ & $1(5)$ & - & $3(15)$ & $16(80)$ \\
\hline \multicolumn{5}{|l|}{ Limitations to lifestyle and activities } \\
\hline Changes to diet & $12(60)$ & $3(15)$ & $4(20)$ & $1(5)$ \\
\hline Changes to alcohol consumption & $7(35)$ & $6(30)$ & $6(30)$ & $1(5)$ \\
\hline Exercise/sports & $5(25)$ & $5(25)$ & $6(30)$ & $4(20)$ \\
\hline Travel & $5(25)$ & $2(10)$ & $6(30)$ & $7(35)$ \\
\hline Unable to plan things in advance & $4(20)$ & $6(30)$ & $9(45)$ & $1(5)$ \\
\hline Clothing restrictions & $2(10)$ & - & - & $18(90)$ \\
\hline Other $^{c}$ & - & $1(5)$ & - & $19(95)$ \\
\hline \multicolumn{5}{|l|}{ Limitations to social functioning } \\
\hline Social activities limited & $8(40)$ & $6(30)$ & $6(30)$ & - \\
\hline Family relations affected & $6(30)$ & $4(20)$ & $9(45)$ & $1(5)$ \\
\hline Friends relations affected & $5(25)$ & $2(10)$ & $8(40)$ & $5(25)$ \\
\hline Relationships with partner affected & $3(15)$ & $3(15)$ & $8(40)$ & $6(30)$ \\
\hline Workplace relations affected & $2(10)$ & $2(10)$ & $8(40)$ & $8(40)$ \\
\hline Other $^{d}$ & $1(5)$ & - & - & $19(95)$ \\
\hline Less interest in sex & - & $5(25)$ & $14(70)$ & $1(5)$ \\
\hline Sexual function issues & - & $3(15)$ & $14(70)$ & $3(15)$ \\
\hline \multicolumn{5}{|c|}{ Sleep difficulties caused by itching or other symptoms } \\
\hline Difficulty staying asleep & $13(65)$ & $3(15)$ & $4(20)$ & - \\
\hline Difficulty falling asleep & $7(35)$ & - & $4(20)$ & $9(45)$ \\
\hline Needs to take naps & $3(15)$ & $7(35)$ & $10(50)$ & - \\
\hline Reduced sleep quality & $3(15)$ & $1(5)$ & $4(20)$ & $12(60)$ \\
\hline Wakes up too early & $3(15)$ & $2(10)$ & $4(20)$ & $11(55)$ \\
\hline Goes to bed early & - & $10(50)$ & $10(50)$ & - \\
\hline
\end{tabular}


Table 5 Spontaneous vs probed impact expressions during the CE portion of the interviews (Continued)

\begin{tabular}{|c|c|c|c|c|}
\hline \multirow[t]{2}{*}{ Symptom Reported, $n$ (\%) } & \multicolumn{4}{|c|}{ Participants, $N=20$} \\
\hline & Spontaneous & Probed & Not Affected & Not Reported \\
\hline \multicolumn{5}{|l|}{ Additional impacts } \\
\hline Scratching until skin is raw/infected & $11(55)$ & $7(35)$ & $2(10)$ & - \\
\hline Decreased quality of life & $3(15)$ & $12(60)$ & $5(25)$ & - \\
\hline Economic burden & $2(10)$ & $6(30)$ & $11(55)$ & $1(5)$ \\
\hline Treatment burden & $2(10)$ & $1(5)$ & - & $17(85)$ \\
\hline
\end{tabular}

$C E$, concept elicitation

${ }^{\mathrm{a}}$ Concern about having children

${ }^{\mathrm{b} S \mathrm{School}}$

'Gardening

${ }^{\mathrm{d}}$ Social stigma

stem was changed to "arms or legs" to make it clearer that participants could respond if they had aching in only one location.

There were no major issues or revisions made to the PGIS-Itch, PGIC-Itch, or 5-D Itch measures; the PGISItch and PGIC-Itch were determined to be appropriate anchor measures.

During wave 1 , the response options were revised for 1 item ("always" changed to "almost always" with regard to how frequently the participant had diarrhea) in the Weekly Gastrointestinal Diary. No further revisions were made to this questionnaire during wave 2 .

\section{Time to complete PRO measures}

The mean (range) time to complete the PRO measures during wave 1 of the interviews was 57.4 (38111) seconds for the AM Itch Diary, 88 (39-100) seconds for the PM Itch Diary, and 252.8 (167-407) seconds (4.2 [2.8-6.8] minutes) for the PBC-40. The mean (range) time to complete the PRO measures during wave 2 of the interviews was 46.5 (28-75) seconds for the AM Itch Diary, 89.8 (47-120) seconds for the PM Itch Diary, and 291.9 (161-420) seconds (4.9 [2.7-7.0] minutes) for the PBC-40.

\section{Discussion}

Qualitative interviews of 20 North American participants with $\mathrm{PBC}$ confirmed the overall content of the Itch Diary and weekly PBC-40 measures in terms of symptoms and disease impact. Qualitative patient interviews are recognized as being an integral part of developing quality of life measures and are recommended by the FDA for the development of PRO measures to support label claims $[15,16]$. Itching-related symptoms were the most commonly expressed symptom concept both spontaneously and overall. Patients reported that itching and fatigue were the worst of their PBC symptoms. Scratching, sleep issues, and work limitations associated with $\mathrm{PBC}$ appeared to have the most important impacts on daily life.

While scratching is a behavior that can be directly observed by others, and is an activity that leaves visible evidence by way of marks and bleeding, itching is a symptom and can only be described by the individual experiencing this sensation. As demonstrated in the current study and others, PBC-related itching can be burdensome for patients [6, 7]. However, previously available tools to assess itch were simplistic measures of worst itch or were not disease specific, or had limited evidence to support their content validity [8]. The Itch Diary was developed to meet the need for a PRO specifically

Table 6 Summary of changes to Itch Diary and PBC-40 as a result of cognitive interviews

\begin{tabular}{|c|c|c|c|c|c|}
\hline Measure & Total Items in Final Measure & Items Left Unchanged & Items Removed & Items Added & Items Revised, n, Description \\
\hline AM Itch Diary & 7 & 4 & 1 & 1 & $\begin{array}{l}2 \\
\text { Item wording revised - } 1 \\
\text { Response scale revised - } 1\end{array}$ \\
\hline PM Itch Diary & 11 & 1 & 1 & 2 & $\begin{array}{l}8 \\
\text { Item wording revised }-5 \\
\text { Response scale revised }-7\end{array}$ \\
\hline PBC-40 & 43 & 35 & 0 & 0 & $\begin{array}{l}8 \\
\text { Item wording revised }-7 \\
\text { Response scale revised }-1\end{array}$ \\
\hline
\end{tabular}


designed to measure the impact of $\mathrm{PBC}$-related itch. Our goal in this study was to confirm the content validity of the daily Itch Diary, which was the primary endpoint. The Itch Diary is independent from the PBC-40 questionnaire, and we wanted to ensure that the diary captured items relevant to patients with pruritus due to PBC. The findings reported here suggest that the Itch Diary will be a useful outcome tool when assessing the efficacy of new treatments for PBCrelated itching.

In addition to the Itch Diary, the current study assessed an adapted version of the PBC-40 using a recall period of "past 7 days" instead of "last 4 weeks." Although the cognitive interviews identified minor issues in the PBC-40, any major changes needed to be discussed and approved by the original developers. After consulting with the original developers, revisions were mainly limited to making minor grammatical changes, such as changing terms mainly used in British English to terms more commonly used and understandable to North Americans.

A limitation of this study is that eligibility was based on self-reported diagnosis of PBC. However, of the 14 participants with additional medical information provided by their physician, all 14 had confirmed PBC. Another limitation is that the patient population was enriched for patients with moderate to severe PBC-related itch. Thus, the applicability of the Itch Diary to the generalized PBC population, or in other conditions, is unknown at this time.

\section{Conclusion}

Qualitative interviews confirmed the relevance and comprehension of the Itch Diary and the weekly version of the PBC-40 as fit-for-purpose measures to assess the relevant symptoms and impacts associated with $\mathrm{PBC}$ and $\mathrm{PBC}$-related itching, and to support the content validity of the measures. Adaptation of the PBC- 40 to a weekly recall period and for North American English was successful. These measures will be useful in evaluating the efficacy of new treatments for PBC-related itch, although further work is needed to fully evaluate the psychometric properties of these measures.

\section{Abbreviations}

CE: concept elicitation; FDA: US Food and Drug Administration; ID: Itch Diary; NRS: numerical response scale; PBC: primary biliary cholangitis; PGICItch: Patient Global Impression of Change for Itch; PGIS-Itch: Patient Global Impression of Severity for Itch; PRO: patient-reported outcome; VAS: Visual Analogue Scale; VRS: verbal response scale

\section{Acknowledgements}

Medical writing and editorial assistance were provided by Erin P. Scott, PhD, of AOIC, LLC, and supported by GlaxoSmithKline, Collegeville, PA, USA.

\section{Ethical approval}

All procedures performed in this study involving human participants were in accordance with the ethical standards of the institutional and/or national research committee and with the 1964 Helsinki declaration and its later amendments or comparable ethical standards.

\section{Informed consent}

Informed consent was obtained from all individual participants included in the study.

\section{Funding}

This study was funded by GlaxoSmithKline, Collegeville, PA, USA.

\section{Availability of data and materials}

Information on GSK's data sharing commitments and requesting access to anonymized individual participant data and associated documents can be found at www.clinicalstudydatarequest.com

\section{Author's contributions}

AVJ, SIB, and DJ contributed to the conception or design of the study and the data analysis or interpretation. MM and LS contributed to the conception or design of the study, acquisition of the data, and the data analysis or interpretation. All authors critically reviewed the manuscript and gave final approval for publication, and all authors take responsibility for its content. All authors meet the criteria for authorship set forth by the International Committee for Medical Journal Editors.

\section{Competing interests}

AVJ is an employee of and holds equity stock in GlaxoSmithKline (GSK); SIB is a former employee of and holds equity stock in GSK, and was employed at GSK during conduct of the study; MLM and LS are employees of Health Research Associates, which received funding from GSK to conduct the study, but have no other conflict of interest to report. DJ received consultancy fees from GSK.

\section{Publisher's Note}

Springer Nature remains neutral with regard to jurisdictional claims in published maps and institutional affiliations.

\section{Author details}

${ }^{1}$ Health Research Associates, Inc., 6505 216th St. SW, Suite 105, Mountlake Terrace, WA 98043, USA. ${ }^{2}$ GlaxoSmithKline, 1250 S. Collegeville Road, Collegeville, PA 19426, USA. ${ }^{3}$ Newcastle University, Newcastle upon Tyne, UK.

Received: 3 August 2018 Accepted: 4 December 2018

Published online: 15 January 2019

\section{References}

1. Hirschfield, G. M., Dyson, J. K., Alexander, G. J. M., Chapman, M. H., Collier, J., Hubscher, S., et al. (2018). The British Society of Gastroenterology/UK-PBC primary biliary cholangitis treatment and management guidelines. Gut. https://doi.org/10.1136/gutjnl-2017-315259.

2. Tsuneyama, K., Baba, H., Morimoto, Y., Tsunematsu, T., \& Ogawa, H. (2017). Primary biliary cholangitis: Its pathological characteristics and immunopathological mechanisms. J Med Investig, 64(1.2), 7-13.

3. Lu, M., Zhou, Y., Haller, I.V., Romanelli, R. J., VanWormer, J. J., Rodriguez, C. V., et al. (2017). Increasing prevalence of primary biliary cholangitis and reduced mortality with treatment. Clinical Gastroenterology and Hepatology: The Official Clinical Practice Journal of the American Gastroenterological Association. doi: https://doi.org/10.1016/j.cgh.2017.12.033.

4. Myers, R. P., Shaheen, A. A., Fong, A., Burak, K. W., Wan, A., Swain, M. G., et al. (2009). Epidemiology and natural history of primary biliary cirrhosis in a Canadian health region: A population-based study. Hepatology (Baltimore, MD), 50(6), 1884-1892.

5. Talwalkar, J. A., Souto, E., Jorgensen, R. A., \& Lindor, K. D. (2003). Natural history of pruritus in primary biliary cirrhosis. Clinical Gastroenterology and Hepatology: The Official Clinical Practice Journal of the American Gastroenterological Association, 1(4), 297-302.

6. Mells, G. F., Pells, G., Newton, J. L., Bathgate, A. J., Buroughs, A. K., Heneghan, M. A., et al. (2013). Impact of primary biliary cirrhosis on perceived quality of life: The UK-PBC national study. Hepatology (Baltimore, MD), 58(1), 273-283.

7. Rishe, E., Azarm, A., \& Bergasa, N. V. (2008). Itch in primary biliary cirrhosis: A patients' perspective. Acta Derm Venereol, 88(1), 34-37.

8. Hegade, V. S., Bolier, R., Oude Elferink, R. P., Beuers, U., Kendrick, S., \& Jones, D. E. (2016). A systematic approach to the management of cholestatic pruritus in primary biliary cirrhosis. Frontline Gastroenterology, 7(3), 158-166.

9. Elman, S., Hynan, L. S., Gabriel, V., \& Mayo, M. J. (2010). The 5-D itch scale: A new measure of pruritus. Br J Dermatol, 162(3), 587-593. 
10. Jacoby, A., Rannard, A., Buck, D., Bhala, N., Newton, J. L., James, O. F., et al. (2005). Development, validation, and evaluation of the PBC-40, a disease specific health related quality of life measure for primary biliary cirrhosis. Gut, 54(11), 1622-1629.

11. Gilchrist, K., \& Vallow, S. (2015). Development of electronic diary in patients with primary biliary cirrhosis. Value Health. https://doi.org/10. 1016/j.jval.2015.03.183.

12. Hegade, V. S., Kendrick, S. F., Dobbins, R. L., Miller, S. R., Richards, D., Storey, J., et al. (2016). BAT117213: lleal bile acid transporter (IBAT) inhibition as a treatment for pruritus in primary biliary cirrhosis: Study protocol for a randomised controlled trial. BMC Gastroenterol, 16(1), 71.

13. Hegade, V. S., Kendrick, S. F., Dobbins, R. L., Miller, S. R., Thompson, D., Richards, D., et al. (2017). Effect of ileal bile acid transporter inhibitor GSK2330672 on pruritus in primary biliary cholangitis: A double-blind, randomised, placebo-controlled, crossover, phase 2a study. Lancet (London, England), 389(10074), 1114-1123.

14. Houts, C. R., Morlock, R., Blum, S.I., Edwards, M.C., \& Wirth, R. J. (2018). Scale development with small samples: A new application of longitudinal item response theory. Qual Life Res: An International Journal of Quality of Life Aspects of Treatment, Care and Rehabilitation. https://doi.org/10.1007/ s11136-018-1801-z.

15. US Department of Health and Human Services FDA Center for Drug Evaluation and Research; US Department of Health and Human Services FDA Center for Biologics Evaluation and Research; US Department of Health and Human Services FDA Center for Devices and Radiological Health. (2006). Guidance for industry: Patient-reported outcome measures: Use in medical product development to support labeling claims: Draft guidance. Health Qual Life Outcomes, 4, 79.

16. Guyatt, G. H., \& Cook, D. J. (1994). Health status, quality of life. and the individual JAMA, 272(8), 630-631.

\section{Submit your manuscript to a SpringerOpen ${ }^{\circ}$ journal and benefit from:}

- Convenient online submission

- Rigorous peer review

- Open access: articles freely available online

High visibility within the field

- Retaining the copyright to your article

Submit your next manuscript at $\boldsymbol{\nabla}$ springeropen.com 